EVS26

Los Angeles, California, May 6-9, 2012

\title{
A123 Grid Battery System Single Rack Evaluation
}

\author{
Daryl Coleman ${ }^{1}$, Jorge Araiza, Loïc Gaillac \\ ${ }^{1}$ Southern California Edison, daryl.coleman@sce.com
}

\begin{abstract}
Southern California Edison (SCE) is performing accelerated life cycle testing on a subsystem of A123's Grid Battery System (GBS). SCE's laboratory testing is being performed on one rack containing 6 modules that provided $100 \mathrm{~kW}$ and $23 \mathrm{kWh}$. The full GBS is a $2 \mathrm{MW} 500 \mathrm{kWh}$ system composed of 18 racks with 8 modules in each. A test profile composed of $1 \mathrm{C}$ and $2 \mathrm{C} 100 \%$ depth of discharge (DOD) cycles was produced to apply 9 cycles per day. Assuming the full system will be used once per day, four months of testing corresponds to the cycles that would be applied over three years of operation. To help track battery performance throughout the testing, Reference Performance Tests (RPTs) are performed every 300 cycles (which corresponds to just over one month). The rack is contained in an environmentally controlled chamber at $20^{\circ} \mathrm{C}$ during all cycling to simulate the thermal conditions in the GBS container.
\end{abstract}

Over 3000 test cycles have been completed on the GBS system. Approximately $10 \%$ decay in capacity has been observed for all power levels. At $80 \%$ DOD the available power has decreased only $3 \%$. After approximately the 1200th cycle, a four month pause in testing occurred. Upon restarting the cycling, a significant decrease in capacity was observed. However, the capacity did not decay as quickly. After about the 2000th cycle, the capacity trend resumed the initial rate of decay. This pause in testing has produced interesting conclusions relating to the relationship of calendar life and accelerated cycling which could have significant impacts on electric vehicle or utility application of lithium-ion batteries.

This report focuses entirely on the laboratory testing of the GBS single rack. Future analysis will combine these results with those of other SCE tests to produce conclusions regarding the application of the GBS on SCE's grid.

Keywords: lithium-ion battery, battery calendar life, battery cycle life, energy storage, smart grid

\section{Introduction}

A123 Systems' Grid Battery System (GBS) units apply technology used in hybrid electric vehicles to meet the power sector's growing need for energy storage [1]. The GBS hybridizes a power plant by adding a multi-megawatt energy storage system to the plant. The GBS uses Smart Grid technologies with energy storage to provide grid stabilizing ancillary services such as frequency regulation, fast ramping, $T \& D$ deferral and spinning reserve to increase power plant efficiency. GBSs increase the capacity, responsiveness, and efficiency of individual power plants and whole power systems. Testing by Southern California Edison's (SCE's) Advanced Technology Organization has been performed on a 
partial GBS. The system being tested is a single rack with 6 modules installed. The complete system is rated at $2 \mathrm{MW}$ for 15 minutes and includes 18 racks with 8 modules per rack. In parallel, a full system is being tested at SCE's Large Energy Storage Test Apparatus (LESTA). The laboratory test is focusing on the fundamental technology that composes the GBS (the battery and battery management system), while the full system test will focus on grid integration and control mechanisms. The single rack being tested in the laboratory for this report does not contain A123 Systems' Smart Grid Domain Controller (SGDC) which is typically installed in a complete GBS such as the GBS testing at the LESTA station.

The GBS is composed of A123 System's lithium-ion Nanophosphate ${ }^{\circledR}$ technology. This chemistry is designed for high power capability and was initially used primarily in hybrid-electric buses and handheld power tools. Based on this proven performance, A123 believes they could be effective for stationary storage applications as well.

SCE is evaluating the performance of the GBS single rack to identify the benefits that this technology can provide. While the full GBS can be used in all of the applications mentioned above, SCE is primarily interested in the system's use on our distribution system. The power capabilities of the system make it useful to provide relief to overloaded circuits and potentially help defer distribution upgrades. SCE will also evaluate the full GBS for renewable integration. This system could help smooth photovoltaic or wind turbine output.

\section{Objectives}

\subsection{System Characterization Testing}

This project aims to thoroughly understand and measure the performance of the single rack of the A123 GBS. To do so, SCE performed an initial preliminary characterization of the rack. This characterization was performed by running several profiles on the system and recording detailed data during the entire test. SCE used this data to:

Verify the capacity of the rack when discharged at various rates

Calculate the roundtrip efficiency of the system

Evaluate effectiveness of the battery management system (BMS)
Determine the thermal performance

\subsection{System Life Cycle Testing}

After the initial characterization of the GBS single rack, SCE used the performance data (electrical and thermal) to assemble a test cycle that could be run continuously on the pack. This profile has been used for over two years to help determine the cycle life of the system. Periodic reference performance tests (RPTs) are performed throughout the cycle testing. These RPTs are used to measure the performance of the system after each interval and identify any decrease in performance as the system ages.

\section{Test Setup and Procedure}

\subsection{Test Equipment}

\subsubsection{Battery Cycler}

Tests are conducted using the Aerovironment AV900 battery cycler. Voltage and current measurements are obtained from the cycler. Temperature measurements for all battery modules are obtained from the rack's CAN Bus. The battery cycler was calibrated locally prior to and periodically throughout testing to ensure the cycler is within factory standards.

\subsubsection{Environmental Chamber}

The ambient temperature during all testing is maintained through the use of an Environmental Chamber. Throughout the course of testing, the GBS rack has been placed in two different chambers, and each was set to maintain at an average of $20^{\circ} \mathrm{C}$. The full GBS includes an HVAC system that will maintain the full system at a similar temperature. In the first chamber the temperature ranged from 16 to $24^{\circ} \mathrm{C}$, while the second controlled the temperatures to within $1^{\circ}(19$ to $\left.21^{\circ} \mathrm{C}\right)$. During the installation of the new chamber, the rack was removed and placed in the lab from June 18 through October 27, 2010. The rack was fully charged prior to this resting period. Over the summer, the temperature in the lab varied greatly. Fig. 1 below shows the temperature profile throughout this period. The rack was not cycled during this period. 


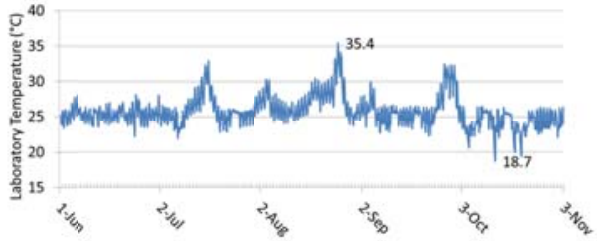

Figure 1: Laboratory temperature June through October 2010

The chamber currently being used is a Thermotron Walk-In Environmental Test Chamber.

\subsubsection{Data Collection}

The primary means of data collection is the battery's BMS CAN communication. Communication on this bus is maintained throughout all testing and used to record module and cell data including voltages and temperatures. To supplement the data collected through the cycler and single rack's BMS, a SmartGuard data acquisition system was installed on the rack. The SmartGuard sensors are used to provide air temperature data for each of the modules in the single rack and to record the ambient temperature in the chamber. One sensor was placed at the air cooling inlet and one at the exhaust of each module. The information is communicated via RS-232 to the computer controlling the battery cycler, where the data is recorded with all other test data.

\subsubsection{Safety Precautions}

Standard safety precautions are taken during the test of the single rack. The pack is continually monitored by the cycler and the test is immediately stopped if communication is lost or the battery approaches the recommended limits (temperature and voltage) as specified by the manufacturer. The limits used for testing the battery are shown in Table 1 . In addition, the chambers where the rack was installed contain smoke detectors that are connected to the building's fire notifier system.

\subsection{Preliminary Testing}

Prior to the initiation of life cycle testing, SCE performed a set of preliminary tests on the GBS single rack to help characterize its performance and understand its limitations.

\subsubsection{Capacity Tests}

For many battery chemistries and other energy storage technologies, the total capacity available changes with the rate at which the power is drawn from the device. SCE's first tests on the rack included capacity tests at different rates of discharge. For each of these, the rack was charged using a constant-current, constant-voltage (CC$\mathrm{CV}$ ) algorithm (as specified by the manufacturer). The charge was limited to a $1 \mathrm{C}$ rate $(32.2 \mathrm{~A})$ initially; then, when the voltage reached $3.6 \mathrm{~V}$ per cell, the current tapered to keep the cell at that voltage. The charge was considered complete once the current dropped below 2.0 A and there was less than a $100 \mathrm{mV}$ difference between the maximum and minimum cell voltage. The rack was allowed to rest for one hour once fully charged. After the rest period, the device was completely discharged at the specified rate. This discharge was performed using rates of $0.5 \mathrm{C}, 1 \mathrm{C}$, 2C, 3C, and 4C. Each discharge was completed at the minimum voltage of $2.0 \mathrm{~V}$, resulting in a 100 $\%$ DOD cycle.

Table 1: Test safety parameters

\begin{tabular}{|c|c|c|c|}
\hline & Units & Min & Max \\
\hline \multicolumn{4}{|c|}{ Safety Limits } \\
\hline Cell Voltage & $\mathrm{V}$ & 1.60 & 3.80 \\
\hline $\begin{array}{l}\text { Battery } \\
\text { Temperature }\end{array}$ & ${ }^{\circ} \mathrm{C}$ & & 45.00 \\
\hline \multicolumn{4}{|c|}{ Discharge } \\
\hline Cell Voltage & $\mathrm{V}$ & 2.00 & \\
\hline $\begin{array}{l}\text { Battery } \\
\text { Temperature }\end{array}$ & ${ }^{\circ} \mathrm{C}$ & & 42.00 \\
\hline \multicolumn{4}{|c|}{ Charge } \\
\hline Cell Voltage & $\mathrm{V}$ & & 3.60 \\
\hline Charge Duration & $\mathrm{h}$ & & 4.00 \\
\hline Charge Current & $\mathrm{A}$ & 2.00 & 32.20 \\
\hline Cell Voltage Delta & $\mathrm{mV}$ & & 100 \\
\hline \multicolumn{4}{|c|}{ Life Cycle } \\
\hline $\begin{array}{l}\text { Temperature before } \\
\text { Charge }\end{array}$ & ${ }^{\circ} \mathrm{C}$ & & 30.00 \\
\hline $\begin{array}{l}\text { Temperature before } \\
\text { Discharge }\end{array}$ & ${ }^{\circ} \mathrm{C}$ & & 30.00 \\
\hline Cell Voltage & $\mathrm{V}$ & 2.00 & 3.60 \\
\hline C-Rate & $\mathrm{A}$ & & 38.64 \\
\hline \multicolumn{4}{|c|}{ RPT } \\
\hline $\begin{array}{l}\text { Temperature before } \\
\text { Charge }\end{array}$ & ${ }^{\circ} \mathrm{C}$ & & 30.00 \\
\hline $\begin{array}{l}\text { Temperature before } \\
\text { Discharge }\end{array}$ & ${ }^{\circ} \mathrm{C}$ & & 30.00 \\
\hline $\begin{array}{l}\text { Battery } \\
\text { Temperature }\end{array}$ & ${ }^{\circ} \mathrm{C}$ & & 40.00 \\
\hline Cell Voltage & $\mathrm{V}$ & 2.00 & 3.60 \\
\hline $\begin{array}{l}\text { HPPC Voltage } \\
(10 \mathrm{~s})\end{array}$ & $\mathrm{V}$ & 1.60 & 3.70 \\
\hline
\end{tabular}




\subsubsection{Efficiency Tests}

A major concern for large-scale energy storage devices is the standby power required to operate them, and the efficiency of the devices to return the power when needed. SCE conducted preliminary tests to determine various efficiencies of the GBS rack.

The first efficiency test investigated the rack's ability to hold energy for an extended period of time: its capacity retention. After a full discharge, the rack was charged completely using the manufacturer's recommended CC-CV algorithm. The rack was then rested for a full 24 hours before beginning a discharge at $1 \mathrm{C}$. The capacity recovered from this discharge was compared with the capacity of the rack when it was discharged one hour after charge, giving the capacity retention of the system over 24 hours.

Another efficiency test was used to determine the round-trip DC efficiency of the GBS rack. With the system fully discharged, a full charge was applied followed by a full discharge with only the one hour rest period in between. The DC efficiency was calculated using the energy inserted through the charge and removed during the discharge.

\subsection{Life Cycle Test Plan}

The bulk of the testing of the A123 GBS rack is accelerated life cycle testing. Cycles are applied continuously with only short rest periods in between to subject the rack to many cycles as quickly as possible. SCE also performs RPTs on the rack periodically throughout the testing to help gauge the current performance capabilities of the pack. From these two components (RPTs and life cycle profiles), a test schedule was compiled to create the overall testing profile for the device.

\subsubsection{Reference Performance Test}

RPTs were performed before the start of the life cycle test and after every 300 cycles are completed. This corresponded to a RPT approximately every 1.5 months.

An RPT is composed of:

- A constant-current discharge at a $1 \mathrm{C}$ rate

- A constant-current discharge at a $2 \mathrm{C}$ rate

- A constant-current discharge at a $4 \mathrm{C}$ rate

- A Hybrid Pulse Power Characterization (HPPC) Test

The constant-current discharges serve as capacity tests to track the capacity of the rack at each power level and the HPPC test is used to identify the power capabilities of the GBS rack. Before each, the pack is charged using the $1 \mathrm{C} \mathrm{CC-CV}$ charging algorithm and a one hour rest period. Similar to the cycling, the voltage limits of $2.0 \mathrm{~V}$ and $3.6 \mathrm{~V}$ are used resulting in $100 \%$ DOD cycles. A preliminary cycle is performed prior to each RPT. This pre-cycle includes a $1 \mathrm{C}$ discharge to 60 $\%$ Depth of Discharge (DOD) and a full charge.

The HPPC test is used as defined in the FreedomCAR Battery Test Manual published by Idaho National Laboratory [2]. The pulses are performed at $4 \mathrm{C}$ (discharge) and $3 \mathrm{C}$ (charge). This test is used to determine the internal resistance and power capabilities of the batteries as a function of DOD throughout the cycling.

\subsubsection{Life Cycle Test}

Stationary installations for large energy storage devices can have quite varied duty cycles based on the specific application. The full A123 GBS would likely be deployed on a utility's distribution circuit and controlled by grid operators to help offset demand during peak hours. To test the most basic use case, the life cycle profile consists of only constant-current discharges to emulate a simple dispatching control. Using data from the preliminary tests, a profile that could be run continuously (while remaining at a safe temperature) was designed. It consists of a combination of $1 \mathrm{C}$ and $2 \mathrm{C}$ charges and discharges with only 30 minutes of rest between each. The profile is shown in Fig. 2. Combining the charges and discharges in the manner shown allows over 9 complete (100\% DOD) cycles to be performed by the system each day. The figure also shows the temperature of the pack when subjected to the cycles. This profile allows for accelerated cycle life testing to be performed while maintaining safe temperatures for the pack.

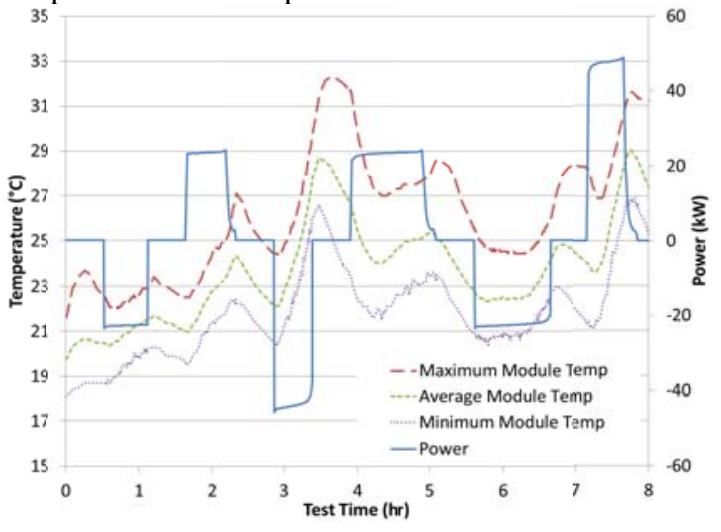

Figure 2: Life cycle profile 


\section{Results and Analysis}

\subsection{Preliminary Testing}

\subsubsection{Capacity Test}

As described in 3.2.1, the system was discharged at various rates to determine usable capacity for each discharge rate. The data in Table 2 is averaged from two discharges at each rate to 100 $\%$ DOD. From the data we can determine that there was essentially no difference in capacity as the system is discharged at higher rates. The lower capacities seen at the lower rates most likely can be attributed to the system requiring more time to fully discharge. Since the passive balancing system is always active in the rack, the balancing circuit is constantly removing energy from the cells. Thus the lower rate discharges had a slightly lower capacity due to the energy lost during cell balancing. The thermal evolution and resulting lower impedance of the cells may also be a factor in this behavior.

Table 2: System capacity and temperatures at various discharge rates

\begin{tabular}{|l|l|l|l|l|}
\hline $\begin{array}{c}\text { Discharge } \\
\text { Rate }\end{array}$ & $\begin{array}{c}\text { Energy } \\
(\mathrm{kWh})\end{array}$ & $\begin{array}{c}\text { Capacity } \\
(\mathrm{Ah})\end{array}$ & $\begin{array}{c}\text { Starting } \\
\text { Module } \\
\text { Temp. } \\
\left({ }^{\circ} \mathrm{C}\right)\end{array}$ & $\begin{array}{c}\text { Ending } \\
\text { Module } \\
\text { Temp. } \\
\left({ }^{\circ} \mathrm{C}\right)\end{array}$ \\
\hline $16 \mathrm{~A}(0.5 \mathrm{C})$ & 22.96 & 32.85 & 21.4 & 23.8 \\
\hline 32A (1C) & 23.50 & 33.98 & 21.5 & 24.3 \\
\hline $64 \mathrm{~A}(2 \mathrm{C})$ & 23.13 & 34.04 & 21.9 & 28.1 \\
\hline 96A (3C) & 22.79 & 34.06 & 22.1 & 31.0 \\
\hline $128 \mathrm{~A}(4 \mathrm{C})$ & 22.44 & 34.03 & 22.2 & 33.0 \\
\hline
\end{tabular}

\subsubsection{System Efficiency}

The capacity retention test was performed as specified in 3.2.2. From Table 3 it is evident that there is a significant capacity loss in a 24 hour period. This loss can be attributed to the load imposed on the battery modules by the BMS (for balancing). Although the energy loss may seem significant for one daily cycle, it is not significant if the battery is cycled continuously during the same period of time. It should be noted that since the rack is not part of a full GBS, this is an abnormal operating condition. A123 has provided a firmware update to reduce decay by cell balancing. However, this update has not been implemented in this test.
Table 3: Twenty-four hour capacity retention test

\begin{tabular}{|c|c|c|}
\hline & Energy (kWh) & Capacity (Ah) \\
\hline Pre-cycle & 23.06 & 33.31 \\
\hline $\begin{array}{c}\text { Following } \\
24 \text { h rest at full } \\
\text { charge }\end{array}$ & 19.91 & 28.86 \\
\hline $\begin{array}{c}\text { Capacity loss } \\
\text { (\%) }\end{array}$ & 17.2 & 13.4 \\
\hline
\end{tabular}

Overall system efficiency was calculated at different discharge rates. Ancillary loads (such as BMS and system fans) were not taken into account for these calculations as they were powered externally. Elapsed time was defined as the time the discharge is started to the time the charge is completed. A one hour rest was included between the charge and discharge. The difference in system efficiency at different rates was small, with only a four percent difference between the efficiencies of the $1 \mathrm{C}$ to $4 \mathrm{C}$ discharge rate (Table 4 ). The lower efficiency rate observed at the $0.5 \mathrm{C}$ discharge rate may have been due to the longer period of time during which the cell balancing circuits were active.

Table 4: System efficiency at different discharge rates

\begin{tabular}{|c|c|c|c|}
\hline $\begin{array}{c}\text { Elapsed } \\
\text { Time (h) }\end{array}$ & $\begin{array}{c}\text { Rate In } \\
(\mathrm{C})\end{array}$ & $\begin{array}{c}\text { Rate Out } \\
(\mathrm{C})\end{array}$ & $\begin{array}{c}\text { System } \\
\text { Eff. (\%) }\end{array}$ \\
\hline 4.8 & 1.5 & 0.5 & 90.3 \\
\hline 3.5 & 1.5 & 1 & 91.4 \\
\hline 3.1 & 1.5 & 1 & 91.7 \\
\hline 2.5 & 1.5 & 2 & 89.9 \\
\hline 2.3 & 1.5 & 3 & 88.6 \\
\hline 2.2 & 1.5 & 4 & 87.2 \\
\hline
\end{tabular}

\subsubsection{Thermal Performance of the System}

Temperature was measured throughout each cycle to determine the temperature rise for each rate in Table 5. For both charges and discharges, the temperature rise was calculated using the maximum temperature at or after the end of each charge or discharge. In some cases the maximum temperature did not occur until several minutes after the charge or discharge was completed; this maximum value was used. However, cooling was seen during the constant voltage portion of some of the charges (as the current tapered). In this case, the temperature at the end of the charge was used, and the charge rises may take into account some of this cooling (and not reflect the absolute maximum temperature rise observed during the charge). In addition, the negative temperature rise for the $1 \mathrm{C}$ charge can be attributed to cooling of the GBS after an elevated initial temperature. Fig. 3 below shows the temperature profile for the $4 \mathrm{C}$ discharge. 
Table 5: Temperature rise for charge and discharge

\begin{tabular}{|c|c|c|c|c|}
\hline \multicolumn{5}{|c|}{ Charge } \\
\hline Rate & $4 \mathrm{C}$ & $3 \mathrm{C}$ & $2 \mathrm{C}$ & $1 \mathrm{C}$ \\
\hline$\Delta^{\circ} \mathrm{C}$ & 9.4 & 7.4 & 3.2 & -1.4 \\
\hline \multicolumn{5}{|c|}{ Discharge } \\
\hline Rate & $4 \mathrm{C}$ & $3 \mathrm{C}$ & $2 \mathrm{C}$ & $1 \mathrm{C}$ \\
\hline$\Delta^{\circ} \mathrm{C}$ & 10.9 & 8.3 & 5.3 & 1.6 \\
\hline 40
\end{tabular}

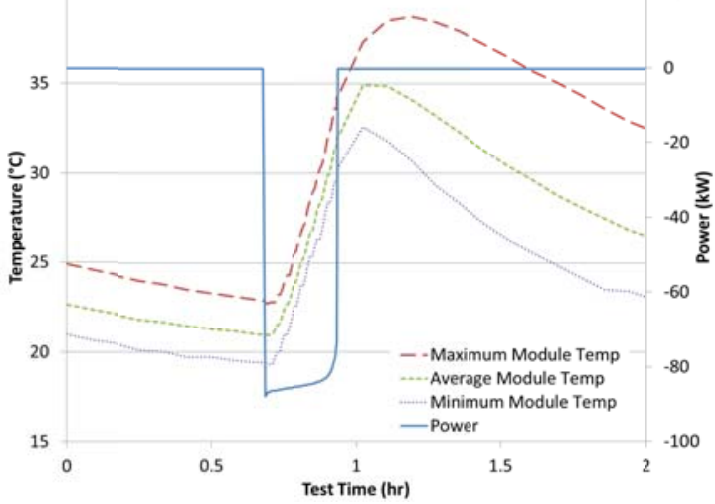

Figure 3: Temperature during 4C discharge

It is also interesting to note that the cooling appeared to accelerate during a low rate charge when the rack was initially at a higher temperature (Fig. 4).

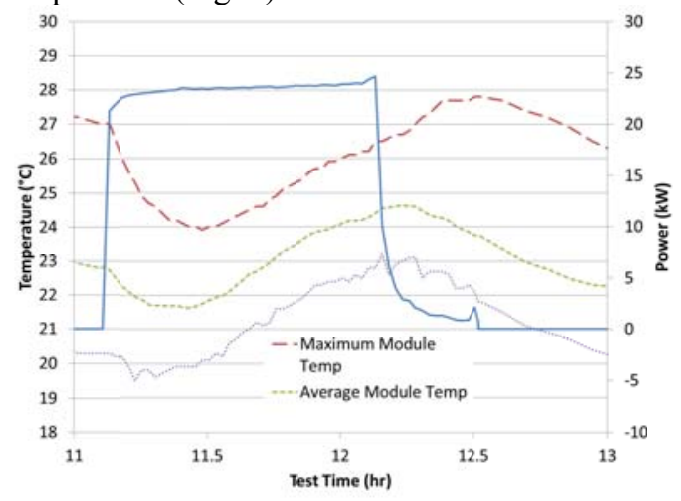

Figure 4: Temperature during $1.5 \mathrm{C}$ charge

\subsection{Life Cycle Testing}

\subsubsection{Results Overview}

Between the initiation of testing in December 2009 and an RPT in August 2011, the rack completed over 3000 cycles. Through these cycles, over $130 \mathrm{MWh}$ was discharged from the rack. A major interruption of testing occurred in the summer of 2010 as a new chamber was installed; no testing was performed between June 18 and October 27, 2010. During much of this period, the rack was not in an environmental chamber, and the ambient temperature was controlled by the laboratory's air conditioning.

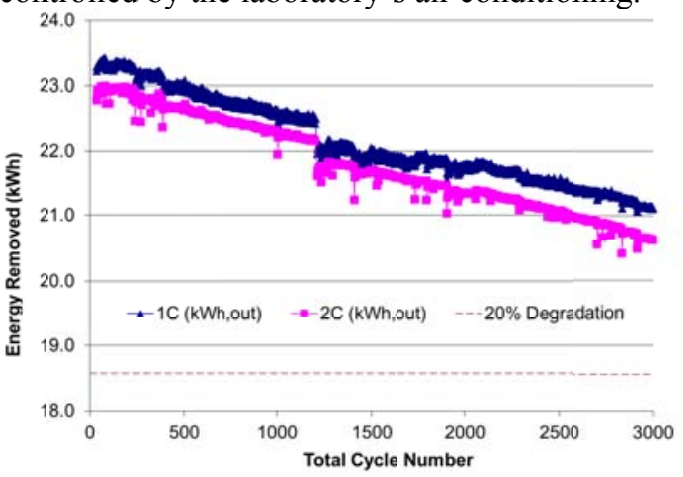

Figure 5: Energy removed per cycle

\subsubsection{Continuous Cycling Results}

Throughout the cycling of the rack, a constant decay in capacity of approximately $0.7 \mathrm{Wh}$ per cycle has been observed from the 1C discharges. This corresponds to a $3 \%$ decrease in capacity for every 1,000 cycles completed. A plot of the capacity versus the cycle number is shown in Fig. 5.

This figure also shows the effect of the interruption of the testing. There was a four month pause in testing after the 1,202nd cycle during which the ambient temperature was not tightly controlled. The rack was left to rest fully charged and exposed to the temperature within the lab (see Fig. 1 for recorded temperature). This break is clearly shown in Fig. 6 below. This figure contains three trend lines, one each for the different colored portions of the data. Initially, as shown by the blue data, the capacity was dropping at $0.8 \mathrm{Wh}$ per cycle. Upon restarting the test, the capacity of the rack was significantly lower, but the rate of capacity decay was also lower for a period of time as shown in green. It is interesting to note that this lower rate continued only until the pack reached a point that could be predicted based on the initial rate of decay. Once the rack reached this point, the rate increased to match that of the initial decay. This final portion of data is shown in purple, and decayed at an average of approximately $0.7 \mathrm{Wh}$ per cycle. 


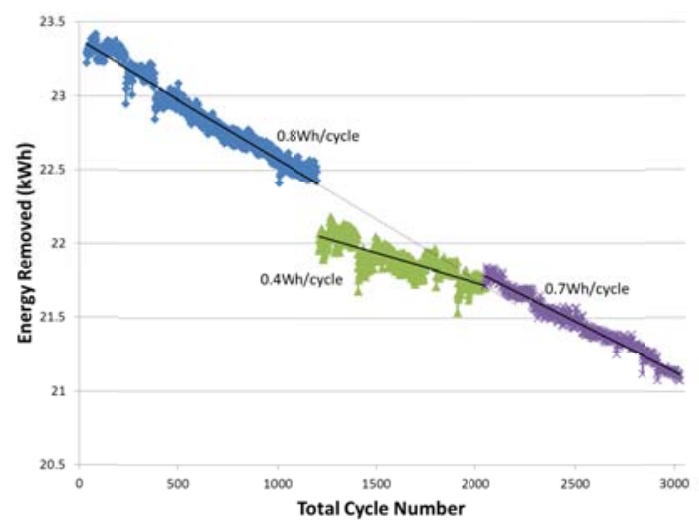

Figure 6: Energy removed by 1C discharges

Throughout cycling, the difference between cell voltages is calculated continually. To ensure adequate balancing, charges are terminated only when the current drops below 2.0 A AND the difference of the maximum and minimum cell voltages (referred to as the "delta") is less than $100 \mathrm{mV}$. There is little variation in the delta after charging. Fig. 7 shows the maximum delta after $2 \mathrm{C}$ charges.

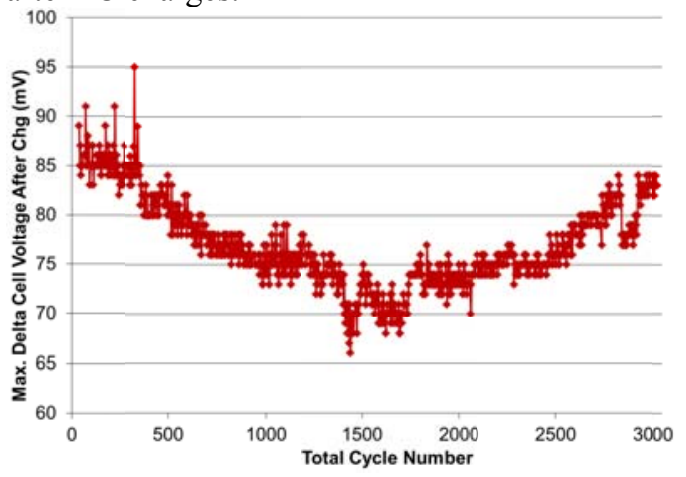

Figure 7: Maximum delta cell voltage after 2C charges

However, the $1 \mathrm{C}$ charging resulted in different behavior. While the $2 \mathrm{C}$ charges are preceded only by $1 \mathrm{C}$ discharges, the $1 \mathrm{C}$ charges come after either $1 \mathrm{C}$ or $2 \mathrm{C}$ discharges. The higher rate of the $2 \mathrm{C}$ discharge is more stressful on the batteries and leads to a larger delta at the end of the discharge. The delta after $1 \mathrm{C}$ charges is shown in Fig. 8. This figure shows the two different end-of-charge conditions as described in section 3.2.1: $100 \mathrm{mV}$ delta and 2 A. Fig. 8 illustrates that when the initial delta was smaller (after a 1C discharge), the balancing was able to improve the cells to well below the delta threshold before the 2 A stop condition was met. However, after the 2C discharges (which produce a large delta), many times the charge was stopped only when the delta reached $100 \mathrm{mV}$; the balancing was the limiting factor. This produced the bimodal behavior in delta after the charges.

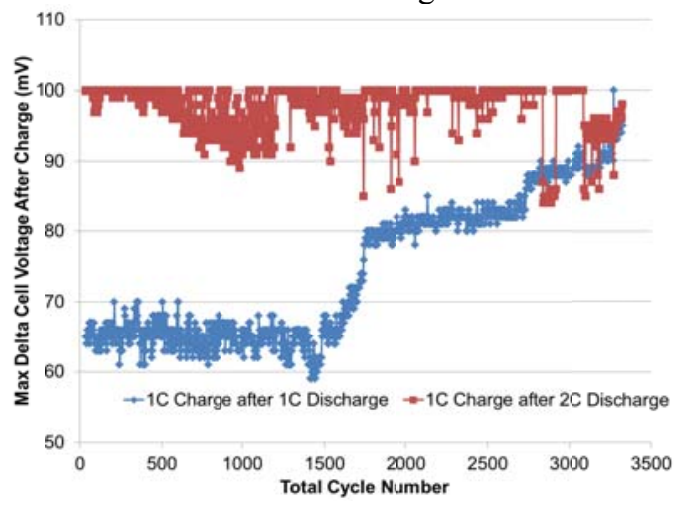

Figure 8: Maximum delta cell voltage after $1 \mathrm{C}$ charges

Looking at only the charges after 1C discharges, these cycles initially resulted in about a $65 \mathrm{mV}$ delta, but this increased significantly as the pack aged. While the most recent trend is a steady rise, the reason for the large jump between the 1500th and 2000th cycle is unknown. The pause in testing occurred around the 1200th cycle; thus does not appear to have affected the balancing of the pack.

All testing is performed based at an ambient temperature of $20^{\circ} \mathrm{C}$ in the environmentally controlled chamber. As described in section 4.1.3, under some conditions, as much as a $9.4^{\circ} \mathrm{C}$ temperature rise was observed by the modules. During the cycling of the rack, however, current is limited to either $1 \mathrm{C}$ or $2 \mathrm{C}$ charges and discharges (with the exception of RPTs).

Fig. 9 below shows the temperature rise observed for all portions of the cycling of the rack. The test profile mixes a $2 \mathrm{C}$ charge and a $2 \mathrm{C}$ discharge with $1 \mathrm{C}$ rate charges and discharges. This accounts for the large deviation between rises for the $1 \mathrm{C}$ rate portions. The $2 \mathrm{C}$ rate portions are always preceded by $1 \mathrm{C}$ rate segments, thus the initial temperature was relatively constant for these tests. The 1C segments, on the other hand, are alternatively preceded by $1 \mathrm{C}$ and $2 \mathrm{C}$ portions. Thus the initial temperatures varied, producing the two different trends each for the charges and discharges.

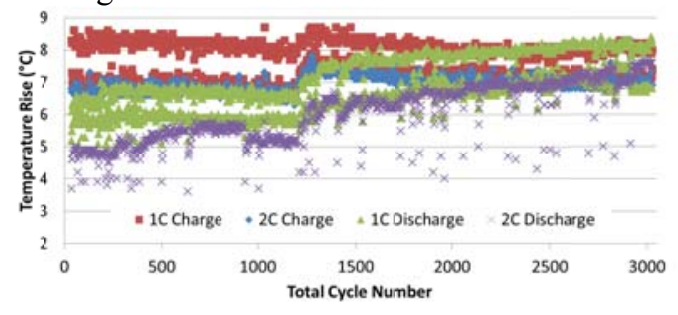

Figure 9: Temperature rises during cycling 
The break in testing (around the 1200th cycle) is visible, but the previous trend was shortly resumed. While the $1 \mathrm{C}$ charge, $1 \mathrm{C}$ discharge, and $2 \mathrm{C}$ charge did have a little change in temperature, a much more significant rise in temperature was observed during the $2 \mathrm{C}$ discharges at the end of testing. This increase shows that as the battery ages, the higher power discharge leads to more heat evolution. The change in battery internal resistance over time is addressed in the next section.

\subsubsection{Reference Performance Test Results}

RPTs are performed as designed approximately every 300 cycles. Due to the pause in testing that occurred in the middle of the test, two additional RPTs were scheduled shortly after the tests were restarted. Thus a total of 13 RPTs have been performed.

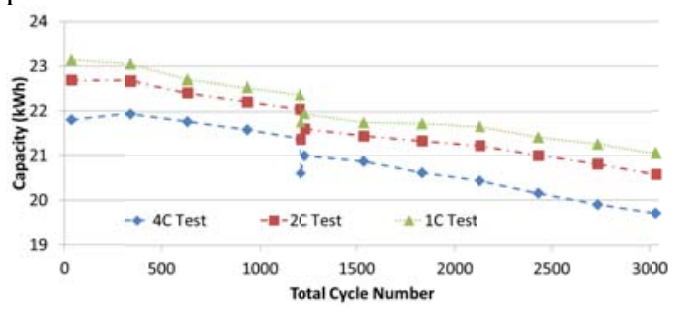

Figure 10: RPT capacity

Fig. 10 shows the results of each of the $100 \%$ DOD capacity tests. Throughout testing, the capacity at a $1 \mathrm{C}$ rate was approximately $300 \mathrm{Wh}$ higher than when the rack was discharged at a $2 \mathrm{C}$ rate. The $4 \mathrm{C}$ discharge resulted in approximately $1 \mathrm{kWh}$ less energy than the $1 \mathrm{C}$ rate. These tests also show the same trends in battery decay as the cycling data. Overall, a constant decay of 0.7 Wh per cycle was observed for both the $1 \mathrm{C}$ and $2 \mathrm{C}$ capacities. These also exhibited the same behavior after the extended pause in testing with an initially decreased capacity but slower degradation. The 4C capacities, however, exhibited a slightly larger rate of decay at $0.8 \mathrm{Wh}$ per cycle. This is one indication of the decay in power capability of the rack.

Fig. 11 shows the decay of the capacity compared to the calendar time of the test. This figure combines all of the $1 \mathrm{C}$ discharges with the RPT data. Similar to Fig. 6, the 1C cycle discharges have been colored to indicate the different regions.

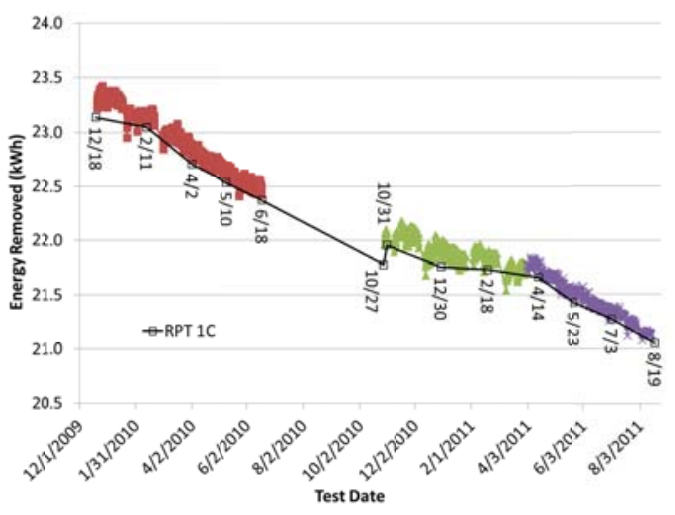

Figure 11: 1C discharge capacity decay vs. time

The rack capacity decayed throughout the extended pause in testing. It appears that this decay was at approximately the same rate as the cycling performed before the test. After the battery began cycling again, a little recovery was seen within a few cycles. Then the lower rate of decay was seen for several hundred cycles until the pack resumed the original rate of decay.

HPPC tests were included in each RPT to determine the internal resistance of the battery. As the DOD increases, the resistance increases significantly. Over the 3,000 cycles applied, the resistance of the pack increased slightly $(8.5 \%$ at $80 \%$ DOD). Fig. 12 shows the discharge and charge resistance calculated from the HPPCs illustrating the large increase in resistance at higher DODs.

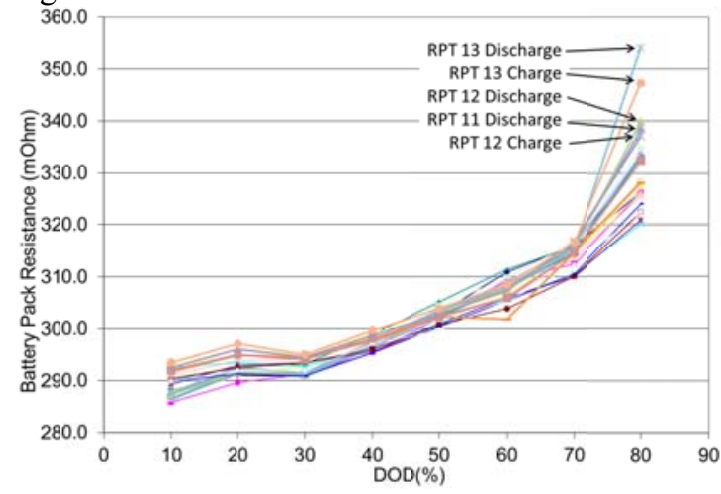

Figure 12: GBS rack internal resistance

Using the resistances, the maximum power available at each SOC was calculated. Fig. 13 plots the available peak power (for 10 second pulses) for several DODs throughout the testing. Similar to other battery technologies, the available power decreased as the battery discharged. However, the data shows that even at $80 \%$ DOD, a pulse of about $95 \mathrm{~kW}$ is attainable. Throughout the cycling, little power degradation is seen at the 
lower DODs, but the power available at $80 \%$ DOD has decreased by nearly $3 \%$.

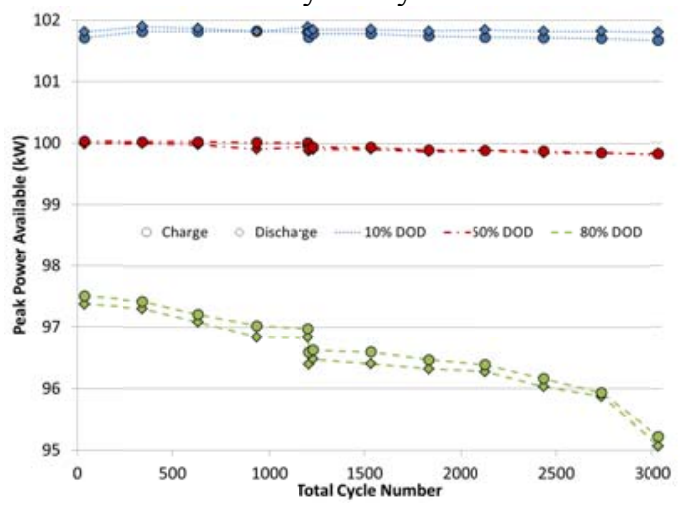

Figure 13: Available power

\section{Conclusions}

Over 3,000 cycles have been completed on the GBS rack. Over the cycling, the batteries have performed well, with only $10 \%$ capacity loss and less than $1 \%$ power loss (at moderate DOD) observed so far. Although the power at $80 \%$ DOD (as calculated using initial capacity) is beginning to fade more quickly, it is interesting to note that for this battery technology, the energy capacity appears to be decaying more rapidly than their power capabilities.

Interesting behavior was observed because of the pause in testing. During the pause, the capacity dropped at approximately the same rate as the previous cycling. This might indicate that calendar life decay is the major factor in battery decay. However, this does not agree with the behavior after cycling. After restarting the cycling, the battery regained a portion of its lost capacity and then began decaying at a relatively low rate. This initial recovery is common for cells after an extended rest period; however, the lower rate afterward is puzzling. One theory is that the rack, while powered down and unable to provide any balancing, exhibited a 'phantom' capacity loss due to cell imbalance accumulating over four months. Upon resuming cycling, the rack was then able to re-balance the cells, resulting in an apparent 'slowing' of capacity fade rate. Once complete, the rack then resumed the original capacity fade rate. While this theory does explain the capacity fade, it is not consistent with the delta cell voltage data recorded (Fig. 7 and Fig 8). It is unknown what mechanisms are combining to produce this behavior, although the plot of capacity per cycle number implies that the pack may be limited primarily due to cycle life.
One of the significant limitations identified with this pack is the cell balancing behavior. Currently, the cells are continually balanced whenever the BMS is active, producing decreased available capacity and low long-term efficiencies. A123 no longer uses this balancing control algorithm on their GBS products, thus this point should not be an obstacle for the performance of a full system.

Overall the GBS rack has shown very low degradation for the intense test profile applied to it. Testing is continuing, but at the current rate, the life of the battery (to $80 \%$ initial capacity) is predicted to be nearly 6,000 cycles. The low power degradation observed thus far indicates the battery to be suitable for a wide variety of applications. Many chemistries become limited due to decay in power capabilities. This rack appears to be able to provide very close to original power specifications for over half of its life.

As testing continues, further investigation will be made into the interaction between calendar life and cycle life decay especially as it relates to the behavior observed around the extended pause. Additional (intentional) pauses may be performed to attempt to duplicate the performance. Simultaneously, SCE will contact A123 to share this behavior and inquire about an explanation.

Currently the same profile is being run on the GBS rack. Additional profiles emulating real applications such as PV output smoothing or ramp controls, might be integrated into the cycling to help evaluate the system in those applications. As testing is initiated on the full GBS at LESTA, SCE will correlate the results from both tests and produce a complete system analysis. This analysis will be used to draw final conclusions about the performance and value of this system to SCE's grid.

\section{Acknowledgments}

The authors would like to acknowledge A123 Systems who provided the battery for testing and support throughout this project.

\section{References}

[1] A123 Systems, http://www.a123systems.com, accessed on 2012-01-25

[2] Battery Test Manual For Plug-In Hybrid Electric Vehicles. US DOE Vehicle Technologies Program, 2008. 


\section{Authors}

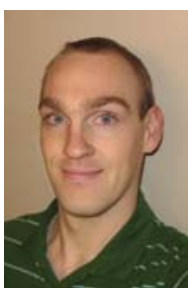

Mr. Daryl Coleman received a B.S. degree in Chemical Engineering from the California Institute of Technology, with a concentration in Materials Science. Currently he works at SCE's Electric Vehicle Technical Center evaluating energy storage systems for stationary applications.

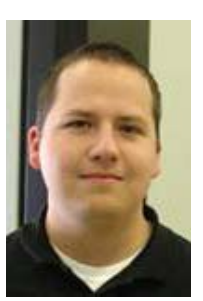

Mr. Jorge Araiza Jr. joined Southern California Edison's Electric Vehicle Technical Center in 2005 as an engineer. Currently he supervises the evaluation of energy storage systems, chargers, and electric/hybrid vehicles. He received a B.S. degree in Electrical Engineering from the University of California, Irvine.

Mr. Loïc Gaillac manages the Energy Storage Group of SCE's Advanced

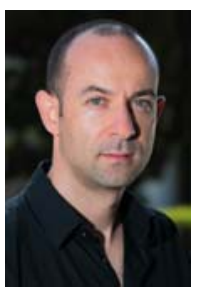

Technology Organization. $\mathrm{He}$ received his Engineering degree in Electrical Engineering from University Paul Sabatier in Toulouse (France) and his Master of Science in Power Electronics and Control Systems from "Ecole Supérieure d'Electricité (Supélec)" (France). 